\title{
Optimization of managerial decisions during innovative-and-investment construction company activities of
}

\author{
Anatoly Egorov ${ }^{1}$, Nadezhda Pilipchuk ${ }^{2}$, Aleksey Selskov ${ }^{3}$ and Kirill Grabovyy," \\ ${ }^{1}$ Nizhny Novgorod State University of Architecture and Civil Engineering, Ilyinskaya St., 65, \\ 603950, Nizhny Novgorod, Russia \\ ${ }^{2}$ Tver State University, Zhelyabov St., 33, 170100, Tver, Russia \\ ${ }^{3}$ LLC "SPE "VARIOS" Smolensk region, Russia \\ ${ }^{4}$ Moscow State University of Civil Engineering, Yaroslavskoe shosse, 26, 129337, Moscow, Russia
}

\begin{abstract}
The article gives a model description of the management processes of the investment activity of a construction company that develops and implements innovative construction projects in the conditions of an acute shortage of external investment resources. Optimization of the series of managerial decisions for the construction of algorithms for managing the innovation and investment activity of a construction enterprise was carried out taking into account the functioning of the investment flow management system: soft management, risk management, crash management. The schemes of restructuring the production, investment and innovative structures of the construction enterprise are proposed. An investment model for the implementation of a specific innovative construction project has been developed and a number of management solutions that meet this model have been identified and designed to neutralize the effects of external adverse perturbations. The application of management solutions of internal, medium and external contours to the management system of investment flows of a construction enterprise as a part of specialized series is substantiated.
\end{abstract}

\section{Introduction}

The search for an effective or optimal from the economic point of view a number of management decisions (NMD) begins with the organization of NMD, designed to neutralize the consequences of various types of disturbing influences $[1,2]$. Different types of disturbing impacts correspond to specific modes of operation of the investment management system of the construction company: soft management, risk management, crash management.

\section{Materials and methods}

The theoretical and methodological basis of the study was the fundamental work of domestic and foreign economists on the organization of innovative and investment activities, the theory

\footnotetext{
* Corresponding author: angela-1309.m@yandex.ru
} 
of assessing the effectiveness of innovation, the theory of making managerial decisions, the theory of project management $[3,4]$. The research was carried out using the methods of economic statistics, as well as general scientific comparative methods (analysis, synthesis, analogy, classification).

\section{Results}

The "soft management" mode parries isolated non-systematic predicted disturbances. Transpose the logic of managing the investment flows management system of a construction enterprise in the soft management mode into a sequence of elementary combinations or management macros using a scheme of functional relationships between the arguments of the management functions of the system [5]. A number of management solutions for the algorithm of managing the investment management system of investment flows of a construction enterprise in the soft management mode is shown in Fig. 1.

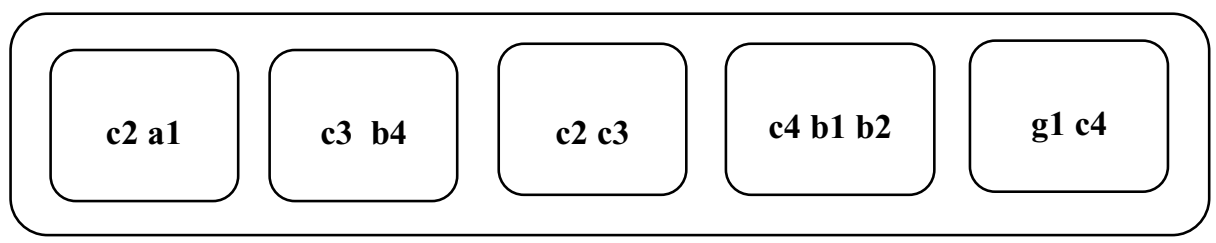

Fig. 1. The NMD for the algorithm of managing the investment flow management system in the softmanagement mode (NMD soft).

After receiving the discrepancy signal between the budget of the construction project (BCP) and the structure of investment flows (IF) due to the impact of a single disturbance, the construction company increases its investment potential by regulating the yield parameters, as the least inert group of management arguments. This logic corresponds to the combination (c2a1), when the peak investment flow is fed by the profit-raising group (c2). In connection with the excess of the estimate of the project in the process of increasing the capitalization of a construction enterprise, a group of arguments for reducing the correlation coefficient of the equipment of the product spectrum is involved. These actions correspond to the combination (c3b4), when the risky investment flow (c3) will be strengthened due to the effect of reducing the correlation component of the factor of intra-firm risks $(\beta)$. Then the funds are redistributed between the peak (c2) and the risk (c3) investment flows to achieve a match between the BCP and the IF, a combination (c2c3). If the correspondence between the investment flow and the budget of the construction project is not reached, a group of arguments for reducing the concentration coefficient is connected to the investment activity. For example, regional (b1) and sectorial (b2) sectors of the target market for construction products and services, which provide the reserve with a financial resource (c4) investment flow. These actions correspond to the combination (c4b1b2) of strengthening the reserve investment flow by reducing the concentration component of the factor reducing the company's internal risks of the construction enterprise. Further, the credit lines for the construction company (g1) are restructured due to the increased reserve investment flow (c4), which is responsible for servicing credit lines from external banking organizations.

In case of success, when the investment flows and the budget of the construction project are coordinated, the investment flow management system is returned to the regular mode of operation, which implies the absence of a temporary increase in the investment potential of the construction enterprise through management of the arguments for increasing profitability and reducing production costs [6].

In the case of low efficiency of the soft management regime, as well as in case of occurrence of non-systematic group disturbances, the investment management system passes 
to the risk management mode. The NMD for the algorithm of managing the investment management system in the risk management mode is shown in Fig. 2.

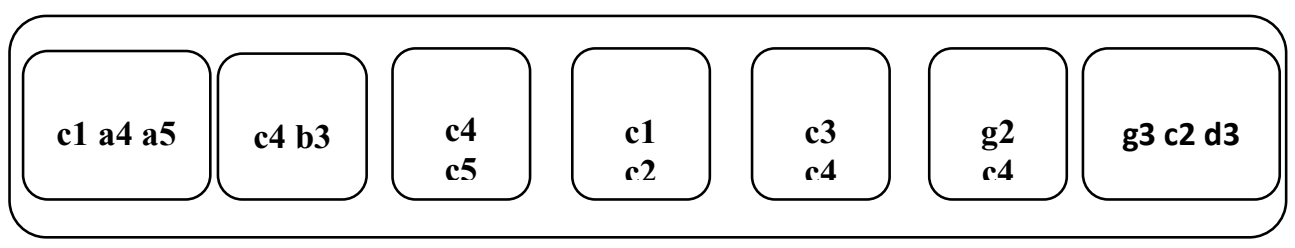

Fig. 2. The NMD for the algorithm of managing the investment flow management system in the riskmanagement mode (NMD risk).

The continuing influence of negative environmental influences dictates the need for the joint functioning of the soft management and risk management regimes. In this case, in the framework of strengthening the investment potential of a construction enterprise in the risk management mode, only those management arguments that are not involved in strengthening the investment potential in the soft management mode are used [7]. This circumstance ensures the uniformity of the distribution of the investment burden on the construction enterprise. The logic of the risk management regime begins with the implementation of a decision to strengthen the capacity of investment flows. Within the framework of this task, the direct investment flow ( $\mathrm{c} 1)$ receives an additional resource by strengthening the investment potential of the construction enterprise by managing the arguments for reducing production costs, for example, (a4) and (a5). These actions correspond to the combination ( $\mathrm{c}_{1}$ $\mathrm{a}_{4} \mathrm{a}_{5}$ ). The reserve investment flow (c4) is strengthened by controlling the decrease in the influence of the concentration coefficient. The combination (s4b3) strengthens the investment potential of the enterprise due to the expansion of the assortment of manufactured construction products and services (b3). At the same time, the reserve investment flow is fueled by the financial resource accumulated on the investment channel of replenishment through the implementation of sub-special activities in the construction company (c5). This action corresponds to the combination (c4 c5).

After carrying out operations to strengthen investment flows in previous operations, resources are redistributed among the channels. These actions correspond to the combinations (c1 c2) and (c3 c4), where the reinforced flows (c1) and (c4) make up, if necessary, investment flows (c2) and (c3). In the event that the compliance of investment flows to the budget of the construction project is reached, the investment flow management system becomes operational. Otherwise, the process of reorganizing the investment structure of the construction enterprise is resumed. As part of this decision, leasing and factoring agents are leased out of the enterprise, and the released resources are channeled to reinforce the reserve investment flow. These actions correspond to the combination (g2 c4). Further, the internal investment funds are reorganized when their specific non-financial resource becomes an innovative construction project, and the financial resource strengthens investment flows. The combination ( $\mathrm{g} 3 \mathrm{c} 2 \mathrm{~d} 3$ ) due to the restructuring of the production investment fund strengthens the peak financial flow (c2), and the production resource (d3) becomes part of the created innovation enterprise. In the case of low effectiveness of the risk management regime, as well as in the event of systematic continuous perturbations of the external environment, the investment flow management system becomes crash management. The NMD for the algorithm of managing the investment flow management system in the mode of crash management by logic (A) or NMD crash (A) is depicted in Figure 3. The continuing negative impact on the investment process of the external environment dictates the need for the joint functioning of the soft, risk and crash management regimes. 


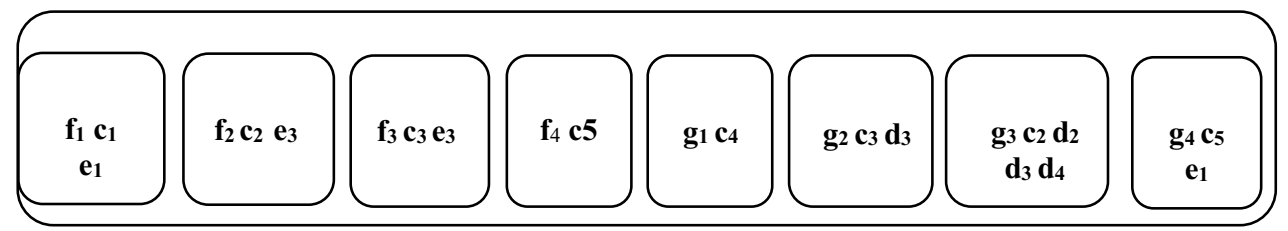

Fig. 3. The NMD for the algorithm of managing the investment flow management system in the crash-management mode, logic (A). (NMD crash (A)).

The Logic Control NMD crash (A) begins at the time of full understanding of the further inefficiency of investment activities and represents a consistent restructuring of the innovation and investment structures of the construction enterprise. The process begins with administrative restructuring (f1) under the influence of the management argument (e1), when the released resources become a part of the direct investment flow (c1). These actions are characterized by a combination of control arguments (flcle1). Further, technological simplification of the innovative solution (f2) under the management of the intellectual resource (e3) is made. The released resources pass to the disposal of the peak investment flow (c2). These actions are characterized by the following combination of control arguments: (f2 $2 \mathrm{e} 3$ ). The next iteration is the restructuring of internal funds that carry out venture activity through the use of subvention benefits (f3). The released intellectual resource is supplemented by the innovative data bank of the construction enterprise (e3), and the financial resource goes to the disposal of the investment and credit channel that conducts a risky investment flow, whose financial resource acts as a reward to shareholders to patent holders. These actions are performed within the combination ( $\mathrm{f} 3 \mathrm{c} 3 \mathrm{e} 3$ ). Further, the innovation object is restructured (f4), the financial resource from which it is transferred to the investment flow of replenishment (c5), which determines the combination (f4c5).

The NMD crash (B) is a NMD, the logic of its management decisions corresponds to the logic (B), when in order to successfully complete the innovation solution, the investment and production structures of the construction enterprise are restructured in the circumstances of an acute shortage of external investment resources.

Control by logic NMD crash (B), Fig. 4, begins at the moment of making a decision on the continuation of the innovation project due to the restructuring of the investment and production structures of the construction enterprise. The reorganization of the investment structure according to the logic of NMD crash (B) differs from NMD crash (A) only in that released resources become part of an innovative construction project.

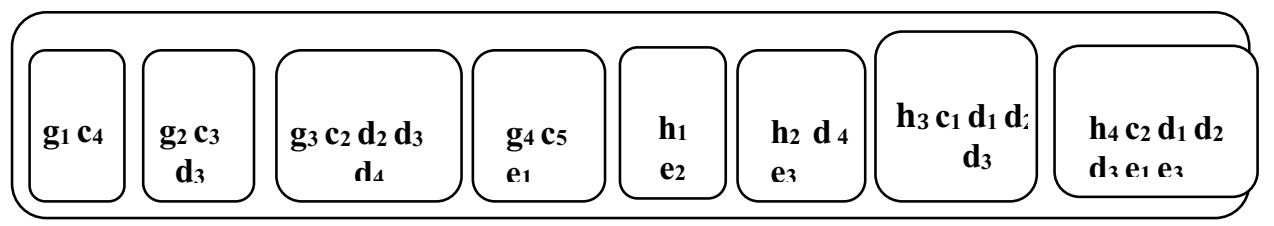

Fig. 4. The NMD for the algorithm for managing the investment flow management system in the crash-management mode, logic (B). (NMD crash (B)).

The restructuring of the investment structure of a construction enterprise begins with the reorganization of relationships with external credit organizations (g1). The released resource for the servicing of credit lines is transferred to the reserve investment flow (c4), which corresponds to the combination (g1c4). The withdrawal of the leasing agent outside the construction company makes it possible to replenish the production resource of the innovative enterprise being created (d3), and the financial resource is sent to the disposal of the risky investment flow (c3), which corresponds to the combination $(\mathrm{g} 2 \mathrm{c} 3 \mathrm{~d} 3)$. Restructuring of domestic investment funds (g3) replenishes the peak investment flow (c2), 
as well as all types of material investment flows (d2), (d3) and (d4) for an innovative enterprise, which corresponds to the combination $(\mathrm{g} 3 \mathrm{~d} 2 \mathrm{~d} 3 \mathrm{~d} 4)$. The final realization of the investment fund (g4) funds replenishes the auxiliary investment flows (c5), as well as the management resource of the innovation enterprise (e1), which corresponds to the combination $(\mathrm{g} 4 \mathrm{c} 5 \mathrm{e} 1)$.

The process of restructuring the production structure starts with the suspension of market research from the point of view of traditional construction products (h1), with the aim of redesigning commercial and marketing structures to study the target market for new construction products and services (e2), which is carried out within the combination (h1e2) $[8,9]$. Further, a consistent reorganization and restructuring of the service structures of the construction enterprise (h2) under the management of an intellectual resource (e3) for the needs of new construction products is carried out. Information on the composition of service providers (d4) is also reoriented to the new requirements of an innovative enterprise, by searching for new counterparties. These actions correspond to a management macro (h2d4e3). Restructuring of external enterprises (h3) is carried out in the direction of conversion to new construction products. This refers to the human resource (d1), the composition of suppliers (d2) and production capacity (d3). Obsolete and non-core equipment is being realized, the financial resource from the sale of which is supplemented by a direct investment flow ( $\mathrm{c} 1)$. The entire set of actions described is described by an elementary combination of management decisions $(\mathrm{h} 3 \mathrm{c} 1 \mathrm{~d} 1 \mathrm{~d} 2 \mathrm{~d} 3)$. The last stage of the restructuring of the production structure of the construction company (h4) is the reorganization and sale of its fixed assets. The human (d1), natural or raw material $(\mathrm{d} 2)$ and production (d3) types of material resources fall into the disposal of the created innovative enterprise when accompanied by administrative (e1) and intellectual (e3) resources. The nonfinancial resources unclaimed by the innovative construction project are realized, the financial resource from the sale of which is supplemented by the peak investment flow (c2), whose functions include final settlement with suppliers in accordance with the project estimate. The above administrative operations are described by the combination $(\mathrm{h} 4 \mathrm{c} 2 \mathrm{~d} 1 \mathrm{~d} 2 \mathrm{~d} 3 \mathrm{e} 1 \mathrm{e} 3)$.

\section{Discussion}

All these types of NMD are integral parts of the overall process of managing the investment activity of a construction enterprise aimed at eliminating the effects of external, negative disturbing influences. From further analysis, we exclude the NMD crash (A), as a result of which the investment activity directed at external innovation projects is curtailed. The process of searching for an effective NMD will be carried out on the basis of NMD that will ensure the completion of an innovative construction project: NMD soft, NMD risk, NMD crash. As a rule, the cost estimate or budget of an innovative construction project is a heterogeneous flow of payments. Throughout the investment period, there is a flow of current payments related to servicing the current needs of an innovative construction project: the salaries of management and financial management, engineering and technical personnel, utility payments. The magnitude of these flows does not change over time, and is similar in character to the annuity investment flow [10]. Then the task of direct investment flow management is reduced to covering the current needs of an innovative construction project. The optimal amount of direct flow is adequate to the volume of current payments.

The process of creating new innovative capacities is characterized by a considerable period of time. In this case, the estimate is divided into stages, for which a number of advance and settlement payments are characteristic. These payments at the current time significantly exceed direct investment flows and are of a peak nature. Accordingly, the issue of their servicing is within the competence of managing the peak flow from investment funds. Then 
the task of managing peak flows is reduced to servicing advance and settlement payments. In addition, the project budget may contain other forms of peak payments, for example, the intermediate purchase of technological lines, test benches, the installation of which is performed in the process of implementing an innovative construction project [11].

Managing risk flows is to cover all unplanned budget costs. For example, emergency situations, shortage of materials and replacement of them for more expensive, costs associated with resolving emerging social conflicts. Such risk flows are unsystematic, the probability of their occurrence by the end of the project is reduced, and they are serviced by a bank fund created on the basis of contracts for the sale of intellectual property rights. Then, the management of the investment and credit channel and, accordingly, the risk flow is the maintenance of unplanned non-systematic costs.

With the approaching end of the innovative construction project, a number of uncertainties that occurred at the time of construction commencement: inflation indicators, refinancing rates, the cost of credit lines, bank deposit interest become evident. In this case, there are unplanned deviations from the project budget. Such deviations, in contrast to the peak, are systematic, therefore, their budget can be calculated and expressed in the form of a credit line. Then the management of the reserve flows consists in servicing systematic deviations of costs in the direction of increasing current and advance-settlement flows with the help of bank credit lines [12]. To formalize the process of managing the innovation and investment activity of a construction company, a number of investment costs must be presented in the form of a sequence of expenses. Even a one-time payment can be presented in the form of elementary expenses having a certain functional purpose, posting of which is carried out at the same time. In Fig. 5 depicts a sequence of investment costs in an innovative construction project, including 16 time intervals that differ in the functional purpose of investment spending. Neighboring intervals can be treated as one, or at different times, which is important when determining the internal rate of return of an innovative construction project by the method of discounting cash flows.

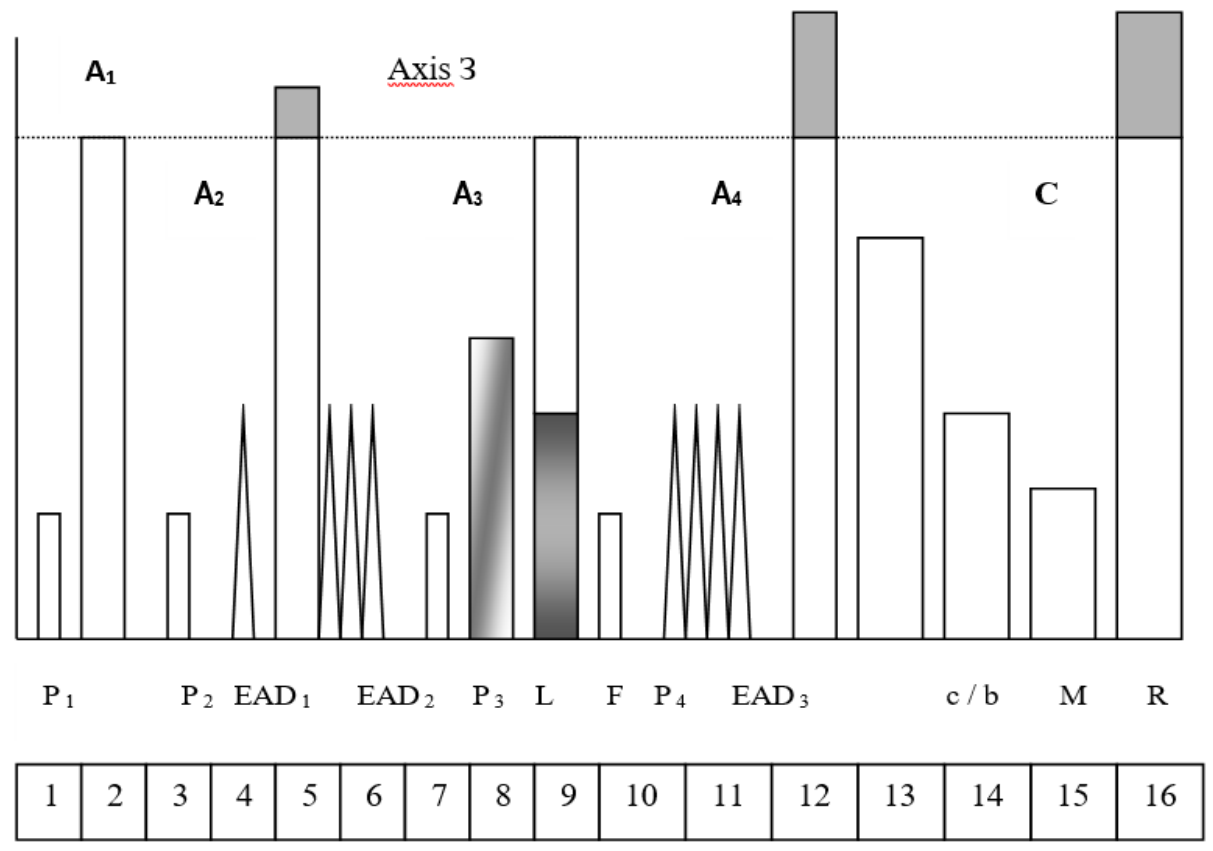

Fig. 5. Scheme of the sequence of investment costs in an innovative project. 

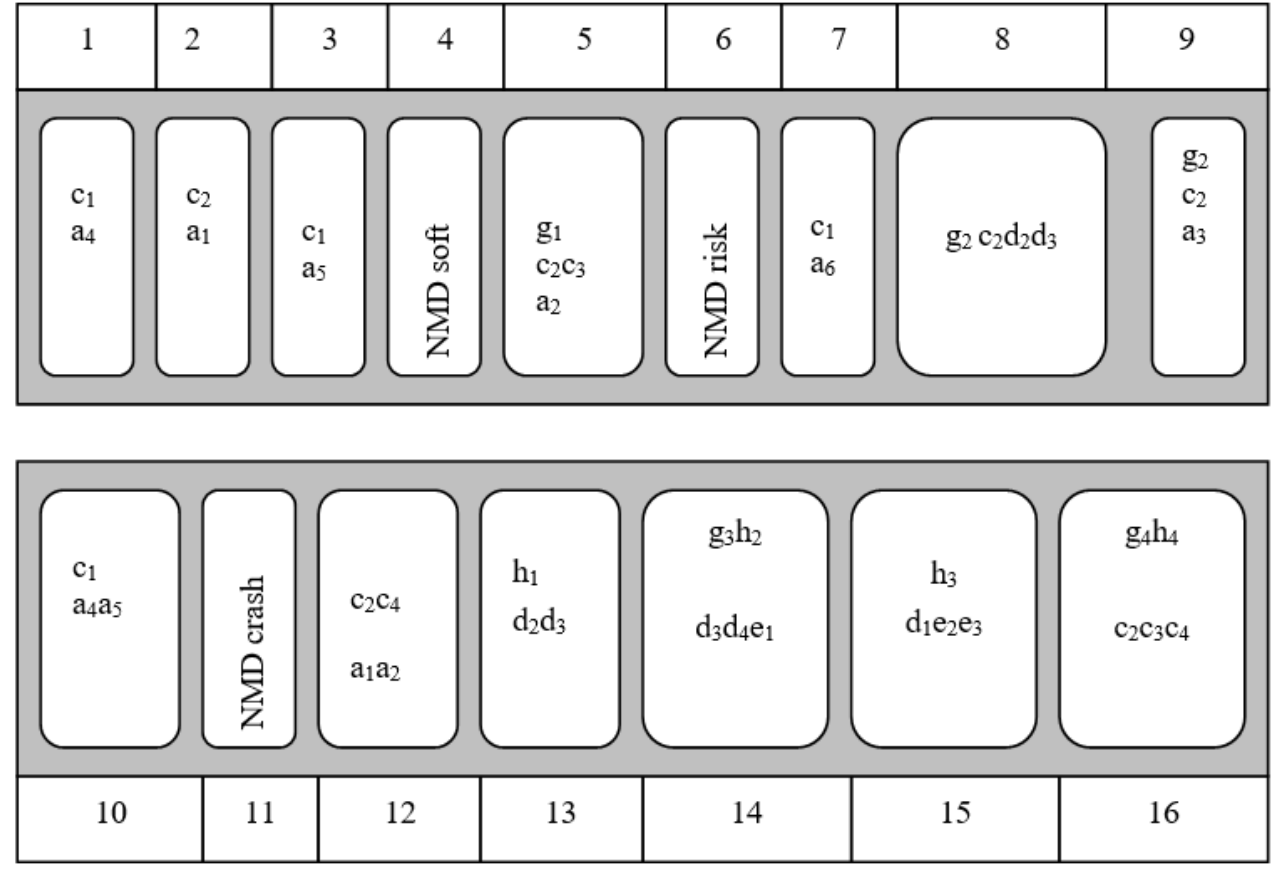

Fig. 6. Model of real NMD for management of investment activity of a construction enterprise.

The proposed scheme is an investment model for a specific innovative construction project, which consists of: A - advance payments; C - final calculation; P - current payments; L - leasing deductions; F- factoring deductions; EAD - parrying external adverse disturbances; $\mathrm{c} / \mathrm{b}$ - the cost of an innovative facility in the form of industrial buildings and structures; M - deductions for the material resource in the form of technological lines, as well as production, service and economic equipment; $\mathrm{R}$ - the cost of an intellectual resource in the form of an intangible resource and its material carrier - a person. The axis (3) determines the annuity rate of advance and settlement payments. Exceeding this norm is a deviation from the budget of an innovative construction project, which is countered by attracting risky and reserve investment flows.

For a specific innovative construction project, the investment model is built on the basis of predicting the characteristics of the external environment, as well as on the basis of experience in implementing similar innovative projects. Therefore, several investment models may correspond to one project. The success or successful completion of an innovative construction project depends to a large extent on the correct choice of the investment model [13].

Define a number of management decisions, corresponding to the investment model shown in Fig. 5. The NMD model is shown in Fig. 6. It should be noted that the NMD intended for conducting the investment activity of a construction enterprise in accordance with the budget of an innovative construction project as management arguments uses external, middle and internal management contours of the investment flow management system that manage the restructuring of structures, investment flows of various types and investment potential of the construction company, respectively. At the same time, the contours of the management of the investment flow management system, when restructuring the innovation, investment and production structures of the construction enterprise are used as part of specialized NMD designed to neutralize the effects of external adverse perturbations. In their composition, the restructuring process is forced and produced in strict sequence: from investment to 
production structure of a construction enterprise. The need for restructuring is explained by the shortage of investment resources, which arises from the impact of unfavorable environmental factors.

When implementing the current investment activity of a construction company in accordance with the model of Fig. 5, the restructuring process is force due to the need to close traditional production facilities at the stage of completion of the current innovative construction project. In this case, those structural elements of the construction enterprise are restructure, the functional purpose of which corresponds to the current needs of the innovative construction project. Thus, when neutralizing the consequences of external influences, restructuring is compulsory consistent: from the least significant to the vital, for the production and investment activities of the construction enterprise.

When carrying out the current innovative activity of a construction enterprise, restructuring is forced by an arbitrary nature and is performed in a sequence that depends on the functional requirements of the budget of the innovative construction project $[14,15]$.

The first iteration of the investment model corresponds to the first current payment (P1). Then the first elementary combination of the NMD or a macro involves management of the direct investment flow (c1), with possible strengthening of the investment potential along the line of reducing production costs (a4), which corresponds to the delay in the assembly and operation of the investment activity of the construction enterprise from the warehouse stock.

The second step corresponds to the first advance payment (A1). To carry out this action, a peak investment flow (c2) is attracted, with a possible connection of the argument for increasing the investment potential (a1) due to the increase in the yield obtained because of adjusting the price list of the manufactured construction products.

The third step corresponds to the second current payment (P2) and is executed at the expense of the contents of the "frame" (c1a5), where (a5) - increases the investment potential of the enterprise due to the delay in advance tax payments in the part of the profit tax.

The fourth step corresponds to the occurrence of a single non-systemic perturbation effect (EAD1), which is compensated by a number of control actions corresponding to the content of NMD soft with possible application of the control functions of the external restructuring contour of the investment flow management system.

The fifth step corresponds to the second advance payment exceeding the permissible level (A2). The body of the advance payment is covered by attracting a peak investment flow (c2). The excess of the advance payment is covered by attracting a risky investment flow (c3) with a possible increase in investment potential due to a change in the structure of the order (a2) or the combinatorial component. In case of ineffectiveness of previous actions, the structure of the credit lines of the construction company through line (g1) may be revised with the aim of reducing the costs of servicing the debt obligations.

The sixth iteration contains a group non-systematic perturbation of the external environment and is parried by a number of control decisions NMD risk.

The seventh step contains the third current payment (P3), which corresponds to the managing "frame" (c1a6), with the possible attraction of an increase in the investment potential of the construction enterprise through the delay in contract payments (a6).

The eighth iteration reflects the leasing relationship (L), which corresponds to the process of transfer of construction equipment and production capacities (d3) and the corresponding supply and storage units (d2) to the innovative enterprise being created from the profile investment fund (g2). In the absence of a profile fund, construction equipment and production lines are purchased from external leasing agents due to the content of the peak investment flow (c2).

The ninth iteration contains the third advance payment (A3) and corresponds to a combination of management arguments (g2c2a3), where the investment potential is supported by the forced sale of the consignment of finished construction products to the start- 
up and service companies (a3). Capacities of peak investment flow may not be sufficient to fulfill the third advance payment due to the implementation at the previous step of leasing relationships with external organizations [16]. Then, to cover the deficit of financial resources involved in the operation of factoring or resale of debt of peripheral enterprises $(\mathrm{g} 2)$.

The tenth iteration contains the fourth current payment (P4), which corresponds to attracting a direct investment flow (c1) with two arguments for reducing production costs (a4) and (a5). The double application of management arguments is explained by the fact that they were attracted earlier and their possibilities to increase the investment potential of the construction enterprise are limited.

The eleventh step is marked by the beginning of systematic continuous disturbances (EAD 3), for example, inflation, whose impact is felt until the completion of the innovative construction project. The influence of this perturbation is compensated by the content of the special series NMD crash.

The twelfth step corresponds to the fourth advance payment (A4) with exceeding the allowable volume of payments. For its repayment, peak (c2) and reserve investment flows (c4) are attracted, with the functions of increasing the investment potential of the construction enterprise connected to the already raised earlier arguments for increasing the yield (a1) and (a2).

The thirteenth step corresponds to the commissioning of industrial buildings and structures, in the process of their creation, specialized investment funds for supply lines (d2) and production buildings (d3) were involved. At this stage, the commercial and marketing structures of the construction company are being re-profiled from traditional to new construction products and services (h1), focused on high-tech niches of the target market (h1d2d3).

The fourteenth iteration reflects the equipping of buildings and facilities with technological lines and equipment (d3), information support and communication (d4), and management resource (e1) in the form of administration administrations and development teams of innovative construction projects. At the same time, a material resource is being transferred to the innovative enterprise being created from profile investment funds (g3). In the regions, the service structures of the equipment warranty service are being redesigned for new construction products and services (h2).

At the fifteenth step, the innovative construction site is filled with a production team $(\mathrm{d} 1)$, commercial and marketing units (e2), and R \& D (e3), the bearer of which (the last two) is a person $(\mathrm{d} 1)$. In the regions, regional enterprises $(\mathrm{h} 3)$ are restructured or re-profiled with a view to reorienting them to new construction products and services.

The last sixteenth iteration corresponds to the final calculation $(\mathrm{P})$, in which three investment flows take place: peak (c2), risk (c3) and reserve (c4), whose joint efforts result in depletion of the investment resources of the construction enterprise intended for the current innovative construction project. At the same time, the financial resources obtained as a result of the restructuring and realization of the fixed assets of the investment and production structures of the construction enterprise serve to strengthen the above investment flows.

\section{Conclusion}

It is easy to see that $13,14,15$ and 16 iterations of the real NMD intersect with the NMD crash series. If neutralization of external disturbance of EAD 3 does not necessitate a complete restructuring of the production structure of the construction enterprise, it is compulsory for the purpose of final settlement according to the estimate of the innovative construction project. Consequently, the resources received as a result of the restructuring of the investment and production structures of the construction enterprise, if necessary, are 
directed primarily to neutralize the effects of external disturbing impacts, and secondarily to pay for the final stage of the construction of innovative facilities.

The resulting series of management decisions reflects a specific investment model that includes all types of investment costs planned for the implementation of the current innovative construction project. Such a model of the RW is the basis for analyzing the effectiveness of a construction project selected for use in the circumstances of an acute shortage of external investment resources.

\section{References}

1. A.D. Ishkov, M.Yu. Mishlanova, K.P. Grabovyi, International Journal of Applied Engineering Research 11(3), 1676-1679 (2016)

2. T. Epifanova, N. Romanenko, T. Mosienko, A. Kupchinskiy, T. Skvortsova, European Research Studies Journal 18(3), 137-148 (2015)

3. P.G. Grabovy, A.E. Naumov, I.P. Avilova, International Business Management 10(7), 1354-1364 (2016)

4. A.Yu. Egorov, A.A. Safronov, A.V. Selskov, Market innovation projects. Methodology for the formation, management and development (Paleotip, Moscow, 2007)

5. P. Brusov, T. Filatova, M. Eskindarov, N. Orehova, A. Brusova, Applied Financial Economics 22(13), 1043-1052 (2012)

6. A.S. Kozlov, E.A. Shnyrenkov, MATEC Web of Conferences 106, 08006 (2017)

7. K. Mohamed, O. Hesham, G. Maged, Journal Of Construction Engineering And Management, 143-2 (2017)

8. E. Romanova, MATEC Web of Conferences 73, 07010 (2016)

9. S.A. Orekhov, A.A. Safronova, Malla Osman Shadi Mustafa, Transport business in Russia 4, 110-111 (2015)

10. R. Willetts, J. Burdon, J. Glass, Proceedings Of The Institution Of Civil EngineersEngineering Sustainability 163-3, 159-166 (2010)

11. A.Yu. Egorov, A.V. Selskov, Innovative economy: information, analytics, forecasts 45, 20-24 (2014)

12. S.A. Baronin, K.Y. Kulakov, Journal of Applied Economic Sciences 11(4), 698-708 (2016)

13. S.T. Cavusgil, T. Kiyak, S. Yeniyurt, Industrial Marketing Management 33(7), 607-617 (2004)

14. B. Amani Suliman, D. Irem, B.M. Talat. Canadian Journal Of Civil Engineering 36(7), 1170-1181 (2016)

15. E.P. Garina, V.P. Kuznetsov, A.O. Egorova, A.P. Garin, S.N. Yashin, European Research Studies Journal 19(2), 55-63 (2016)

16. A.B. Ngowi, E. Pienaar, A. Talukhaba, Building And Environment 40(1), 135-141 (2005) 